\title{
REVIEW ON THE PERFORMANCE OF THE CONTROL STRATEGIES USED FOR SMART BENCHMARK BASE ISOLATED BUILDING
}

\author{
RiniDey $^{1}$, PurnachandraSaha ${ }^{2}$ \\ ${ }^{I}$ M. Tech Student, School of Civil Engineering. KIIT University, Bhubaneswar, Odisha, India \\ (Email: rdey789915@gmail.com) \\ ${ }^{2}$ Senior Associate Professor, School of Civil Engineering. KIIT University, Bhubaneswar, Odisha, India
}

(Email: dr.purnasaha@gmail.com)

\begin{abstract}
Building structures are more susceptible to the ground motion and caused high level of damage to the lives and properties. Hence the safety parameters and the serviceability have to be maintained by reducing the induced seismic effect on the building structure. The aspire of this paper is to review a state of the art of researches on effectiveness of severalcontrol strategies such as, Semi-active Variable Damper, Magneto rheological (MR) dampers and piezoelectric friction dampers Resetting Variable Stiffnessalong with the controls strategies such asFuzzy Logic Control (FLC), ELM with LQG and Clipped Optimal Control Method Supervisory variable Fuzzy Logic Control(SVFLC) Skyhook Semi active control, Lyapunov Control. The benchmark problem on smart base isolated benchmark building developed evaluation criteria to compare among the control strategies along with the supplementary devices. Assimilating the performances of the control strategies it has been observed that the performance of MR damper with Supervisory Fuzzy Logic Control (SVFLC) is robust for all the earthquakes considered in the benchmark problem.
\end{abstract}

Keywords: smart base isolated benchmark building, control strategies, Magnetorheological (MR) dampers, piezoelectric friction dampers, Semi-active Variable Damper, Fuzzy Logic Control (FLC).

\section{INTRODUCTION}

In recent years Base isolation has proven to be an efficient technique by the act of decoupling the structures from ground excitations for Seismic protection in structure. Progressively well-précised benchmark problems have been introduced for studying on the responses of control strategies for structures applied to the seismic andwind excitationlike building and bridges, by successful endeavor of ASCE (American Society of civil Engineering) structural

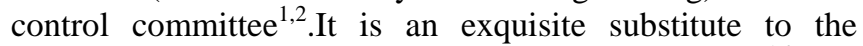
expensive experimental benchmark test structure ${ }^{1,2}$.The main objective is to establish the Benchmark Model s shown in fig 1 . is to Compare and compete byproviding a well expounded structure with a broad set of chosen parameters sets as ina control techniques or control strategies including strategies, algorithm sensors, and deviceson a standardized Systematic structural model or benchmarked model to evaluate the result ${ }^{7}$.A pre defined analytical benchmark problems are itself asplendid way to incorporate the practice of providing nonlinear passive dampers to tether the bearing displacement, which initiates the forces in structure at the level of isolation ${ }^{6}$. There are certain novel devices developed as an excellent alternative of passive nonlinear devices which are active and semi active devices amongst them the remarkable devices such as Magnetorehological damper (MRD) ${ }^{10,12,11,13,2}$, Piezoelectric Damper(PFD $)^{9}$,Friction Pendulum System (FPS $)^{7,4}$ ,Resettable stiffness damper ${ }^{18}$ has come to be more liable and efficient. During strong earthquakes enhanced in the near Fault area the structures are induced to large displacements ${ }^{1,2}$. Many control strategies have been utilized with the proposed devices for the better performance which provides an inherent robustness and capability to deal with sudden uncertainties such as a various feedback control strategies like Fuzzy Logic Control(FLC),Supervisory Fuzzy Logic Control(SVFLC),Linear Quadratic Gaussian(LQG),Clipped Optimal Control, Skyhook Semi active control, lyapunov control etc ${ }^{5,6}$.

\section{BENCHMARK PROBLEM}

An Idea of the Benchmark model leads to a particular benchmark problem which has been adopted from a $\mathrm{L}$ shaped 3D eight storey Building Structure of $54.3 \mathrm{~m}$ width and $82.4 \mathrm{~m}$ length with a bracing of steel which is enable to the lateral torsional coupling forces, analogues to the USC hospital in Los Angeles California. The intention of the study of the benchmark problem is to evaluate the performance by comparing different types of control strategies, Generalized algorithms with devices under a systematic standardized predefined building structure or a benchmark building subjected to the earthquake excitation(Lateral force).The braced supported Superstructure at the perimeter of the building resting on the reinforced concrete base slab over the integral concrete beamsbelow that the each columns drop panels are located precisely. The members of the superstructure as in beam, column, bracing, slab has been given detailed in the figure, the isolation devices are connected between the footing and 
the drop panels under the column $1,4,6,7$ as shown in the figure below. The base and the floor slab are considered to be rigid and the entire superstructure has been modeled to be in 3D linear elastic system. The whole superstructure is simulated on the basis of 3 master degree of freedom (DOF) per floor at the mass centre. The combination of DOF of the model is précised to be $24 \mathrm{DOF}$ at the superstructure and $3 \mathrm{DOF}$ at the isolation panel composed of 27 DOF.The Damping Ratio of the superstructure has been considered to be $5 \% 1,4,6$.

\section{EVALUATION CRITERIA}

Every individual Benchmark problem is characterized by the performance evaluation criteria relatingand comparing with several adopted control strategies along with the various devices. The performance of a particular study is evaluated with the performance evaluation criteria consisting of nine performances indices as shown in the fig $21,6,7,12$.

\section{USED DEVICES IN SMART BASE ISOLATED BENCHMARK BUILDING}

\subsection{Lead Rubber Bearing (LRB)}

It is a nonlinear bearing device which has been introduced to be a passive control system it consists of rubber or elastomer, reinforced steel and lead. Rubber and the steel plates are implanted vertically where the steel plates are provided to achieve a vertical stiffness and can sustain the gravity loads as well as lateral flexibility and restoring the energy due to the rubber which works as a spring or elastic material, whereas lead in the core position deals with the damping which essentially deforms plastically in the direction of seismic ground motion.

\subsubsection{Equivalent Linear Model(ELM) with Linear \\ Quadratic Gaussian (LQG) Control Design}

A nonlinear structure needs a linearizedmodel approach to be able to explain nonlinear responses of the structure in controlled condition. This linearized model is improvised by LQG controller, The objective of a typical LQG controller is to obtain the control gain that quantifies the optimizationproblem3 The approach of Equivalent Linear Model (ELM) is required to obtained the use of an Linear Control theory for a nonlinear structure response. Thedesign of ELM a control theory is necessaryand to design a control theory an ELM isnecessary this cyclic process can be solved by iterative method3. The augmented model has been shown in fig 4 .

\subsection{Friction Pendulum System (FPS)}

It corresponds to the sliding bearing which is associated with two horizontal steel plate where the concave surface allows the cylindrical bearing part to freely move with the interaction of corresponding ground motion to be able to slide spherically as shown in fig 6, by sliding it dissipates the energy due to frictional action.

\subsection{Magnetorehological Damper (MR Damper)}

Magnetorhelogical damper is a Controllable fluid viscous Damper (CFVD) which consists of a Controllable fluid which combines with magnetic action and rheological properties. MR fluid can be manipulated with the magnetic field instantaneously that is why it is also noted as a smart material. In the absence of a magnetic field it behaves like Newtonian fluid.MR Fluid contains of a hydro-carbon oil or a silicon oil along with the ferrous particles. When a strong magnetic field exposed to the fluid the particle aligned in a chain which forms a long strand of magnetic flux of the particles which combat the shear and changes the apparent viscosity of the fluid 17

\subsubsection{Feedback Control Algorithm}

The control strategies are adopted from a feedback control system, this is not a trivial task to obtain an appropriate feedback control algorithm. The seismic response to the structure during ground motion in base isolated building are supervised by the control strategies involves using active or semi active control strategies such as Clipped bilinear displacement-dependent control (BDDC) clipped optimal control using H2/LQG7,3displacement-acceleration domain algorithm, frictional force control fuzzy logic control8,9generalized linear quadratic regulator(LQR) Hoo control, linear quadratic regulator (LQR), maximum energy dissipation algorithm, modified clipped-optimal control ,modulated homogeneous friction algorithm, optimal control optimal fuzzy logic control, predictive control , relative displacement domain control (RDDC) , sliding mode control ,sliding mode fuzzy control, supervisory fuzzy logic control tuned interaction damping (TID) and viscoelastic friction (VEF) controller 6.

\subsubsection{Fuzzy Logic Control (FLC)}

A Fuzzy logic Controller is utilized with semi active device MR Damper, This logic control deals with the inherent robustness and abilities to manage with the uncertainties and non linearites of the system.FLC is an analytical simulation to the function of natural logical behavior of the human brain, Fuzzy logic rules comprises with the IF-THEN rule to achieve an optimal response input output relationship of the system,it can also stabilize the hysteretic behavior of the structure subjected to the seismic force. The design steps of FLC given below

\subsection{Ascertain input-output variable}

In this step the decision have to make on the basis of the response type which guides to choose the input variables, by then only the procedure can be prepared for the next step to achieve the desired parameter of output variables corresponding to the input variable.

\subsection{Input Variable Fuzzification}

After the first procedure the quantifiable input is obtained by fuzzfication interference maps in the composition of a crisp set to a fuzzy linguistic value. 


\subsection{Inference engine}

The interference engine confines with both the activity of mapping the input variables to the output variables and making the decision based on the results achieved from executing these rules. It works on IF-THEN rules where IF implies antecedent and THEN implies consequence

\subsection{Defuzzification of output variables}

The function of the defuzzification mostly concise with Fuzzy control algorithm, it evaluates mapping obtained from the space to the fuzzy outputs as the crisp set output12.Figure 8 shows the model of FLC.

\subsubsection{Genetic Algorithm (GA) optimized FLC}

GA is first initialized by university of Michigan in the year of 1975, it is an optimization method of free stochastic. This method comprises with three modular steps which are selection of the operator, crossover and the mutation. Genetic Algorithmis a parallel search procedure which can be optimized in both discrete and continuities method of problem and is a less prone to be entrapped in a system of the procedure for being a stochastic in a nature. The Search engine of a fuzzy surface is a vast procedure since the individual variable of fuzzy sets are limitless because of the multidimensional space where thecombinations of the various component properties of fuzzy system conceding to the SVFLC, ANFS, Artificial neural network process, nuero fuzzy interference of fuzzy system are defined varyingly 17 , henceforth the GA has been initialized to obtainthe optimizedproperties of the automatic generated FLC to the search surface12.Basically employing the GA is to determine the FLC to obtain the appropriate parameter member function8.

\subsubsection{Supervisory Variable Fuzzy Logic Control (SVFLC)}

Supervisory Fuzzy Logic (SVFLC) feedback controlalgorithm, has been proposed to generate a smart and intelligent response to the earthquake6. The operation of SVFLC is to evaluate between the controllers which is to be modified on the basis of lower level performance of the controller damper.During the earthquake individual subFLC send different command voltages to the semi active controller where the function of SVFLC is to determine the two command voltages on the basis of fuzzy interference system in a real space time.SVFLC strategy has been updated to modulate the performance of controller by manipulating sub-FLC developed in the earthquake ground motion in real time to limiting the actions of superstructures responses like floor acceleration 11,6.

\subsubsection{Clipped Optimal Control (COC)}

There are numerous Clipped Optimal Control which have been introduced for a benchmark building problem among them the H2/LQG clipped -optimal control algorithm is used by controlling the voltage command applied on the semi active devices as in MR Dampers, also a new control algorithm named smooth-clipped-optimal control has been optimized with LQG method which has been initiated to explain the behavior of MR Damper to reduce parameters of earthquake response. This control strategy has been developed to design the controller of a system to be able to generate a desired optimum control force by MR Damper corresponding to the voltage control law 2,6,7

\subsubsection{SkyhookSemi active Controller}

A skyhooksemi active controller has been also considered to evaluate the benchmark problem among all the various control strategy. The Skyhook semi active controller runs on the basic fundamental idea of connection of the one end or hooked at the non vibrating frame at the top(representing the sky frame) and another end connected to the mass, because of this configuration the system is called skyhook damper given in figure 9 , hence the damping force of the system is developed opposite to the velocity or the spring force, such an idea is imaginary to be developed in a passive way but it can be depicted by an active control strategy, such a concept imitating damper is called skyhook control. The skyhook controller enable to reduce the absolute mass acceleration rather than a relative mass acceleration governed by other traditional dampers including the efficiency of the reducing the resonant frequency developed from the system7,8,2,18.

\subsubsection{Lypunov Control}

The Lyapunov control has been represented to control the friction isolation in the benchmark problem, lyapunov function is designed to represent the assurance of asymptotic stability within a optimum range of operation where MR Damper are governed to minimize the effect of the earthquake response on the structure, the basic principal of the Lyapunov semi active control algorithm is generalized for seismic excited time varying damping system. 7,4,12.

\subsection{Piezoelectric Damper (PED)}

PiezoelectricFrictional dampersare used vividly for reducing the earthquake response in the study of benchmark problem of the base isolated structure,this Damper typically consists of two sliding parts which generates the friction force to absorb the energy9.Due to the uncertain ground motionresponse a controllable normal force is required to achieve the desired dissipation of energy for the ground excitation in different levels. Piezoelectric materials have an exquisite procedure to reverse the voltage developing due to the mechanical applied stress to the applied voltage to the produced stress/strain phenomenon. A Piezoelectric Friction Damper is modified with the piezoelectric stack to provide a desirable friction force to the normal force of a friction damper 9

\subsubsection{Semi-Active Controllers}

Due to the semi active device depending upon the control strategy which enables the device to predict the slip force throughout the seismic excitation initiatesa modified control theory, where FLC has been regulated for the device to enhance the performance of the PFD during excitation. The 
Friction force of the piezoelectric is needed to be optimized by the semi active control strategy due to the imprecision, uncertainty, discontinuous, non linear behavior of the excitation of a ground and the isolation system of benchmark problem. The Fuzzy Logic control has been implemented to evaluate the complex nonlinear system 9the flow chart of the FLC with Piezoelectric Damper has mentioned in fig 10,11

Steps for evaluating the FLC Design

I. Input and Output variables are initialized primarily.

II. The linguistic values are converted from the crisp values which is attained by signifying the membership function to the individual variable

III. A rule base of fuzzy interference is originated to associate the input and output set.

IV. By appointing the method of defuzzification the fuzzy quantity of the output variable is converted to non fuzzy discrete value ${ }^{9}$

The developed control strategy is used to compare the performance by employing two methods of one is knowledge based hierarchical fuzzy controller another one is GA optimized FLC design

\subsubsection{Supervisory fuzzy logic controller}

The amplitudes (velocity and deformation) of the isolation level are highly differentiable for far-field and near-field earthquake the procedure of containing the optimized decision model has been made by SVFLC. Flowchart in fig 12

I. A Fuzzy Controller is involved to obtain the PFD command Voltage

II. SVFLC has to be operated through online to deal with the performance of controller with the uncertainty of ground motions where the displacement and the velocity parameters of isolation system are employed as a two input variables where as command voltage are employed as a single output variable 9 .

\subsection{Resetting stiffness device}

The resettable stiffness damper has been introduced recently for the application of smart benchmark building and bridges for the ground excitation. Utilizing the high pressure gas a full scale high performance resetting semi active stiffness damper has been analyzed and obtained the performance by evaluating the hysteretic behavior of the device experimentally through the procedure of simulation on the benchmark building. The Resetting stiffness elements of the Damper or the devices essentially alters with the stiffness not damping, The prototype of this device has been implemented by incorporating the high pressurized gas nitrogen. The force generated by the gas can be correlated by the linear spring stiffness on the basic principle of device is that it would be perform like a controllable spring in order to be manipulate with the structural stiffness and can be change in real time. A High stiffness value can be gained by Utilizing a standardized hydraulic or pneumatic devices, shown on fig 13

The optimal specification of the device is to conceptualize the conventional stiffness variable form to concentrate on resetting the stiffness parameter where the stiffness parameter can be varied into maximum value to the minimum value of zero. A linear spring stiffness is defined by the force generated as a function of piston area by closing the valve and by opening the valve acts like releasing the stiffness where the linear spring model can be utilized by developing semi active control theory with corresponding device.

\section{COMPARISONAMONG THE CONTROL STRATEGIES}

Table 1 representsthe maximum values of evaluation criteria of all earthquakes specified in the Benchmark Problem.Observing the numerical values of the evaluation criteria from the table 1,SVFLC-1using Controllable fluid Viscous damper proposed by Gary Reigles controls thepeak base shear( J1),peak structural shear (J2 ) and peak base displacement (J3) significantly. Whereas (J7) RMS base displacement indices and (J8)RMS floor acceleration performance indicesproposed by Francesc Pozo, Arturo Rodrıguez, Leonardo Acho, Yolanda Vidal, Jose Rodellar has a better performance using the clipped optimal with MR Fluid Damper than other semi active control result, where as the normalized peak control force (J6) is better among all the systems tabulated proposed by Pozo et al.by using sample controller LQG with MR Damper.

\section{CONCLUSION}

Concluding with overall remarks obtained by interacting the results with each other SVFLC-1 with Controllable fluid viscous Damper semi active control theory is more relevant and more robust to the response reduction of the structure achieved by Damon reigles for response reduction of peak base shear J1corresponding to the Peak Structural Shear J2 and Peak Base displacement J3 of the structure simultaneously and by using MR Damper cooperating with Clipped optimal and sample controller LQG experimented by byPozo et al. , has given a emphatic result, the ultimate result among all the experiment the control System accomplished by Damon reigles is the robust one in response reduction of benchmark problem.

\section{REFERENCE}

[1] Narasimhan. S,Nagarajaiah .S,JohnsonE.A and Gavin H.P., "Smart base-isolated benchmark building. Part I:problem definition" Structural Control and Health Monitoring,13, 2006, pp 573-578

[2] Nagarajaiah.S,Narasimhan .S"Smart Base Isolated Benchmark Building Part II: Phase I Sample Controllers for Linear Isolation System" Journal Of Structural Control,0, 2002,pp1-6 
[3] ErkusBaris ,Johnson.A.Erik, “Smart Base Isolated Benchmark Building Part iii :A Sample Controller For Bilinear Isolation" Structural Control and Health Monitoring, 13,2004 ,pp 605-625

[4] Narasimhan.S,Nagarajaiah.S,Johnson E.A "Smart Base Isolated Benchmark Building Part IV: Phase IISample Controllers for Nonlinear Isolation Systems"Structural Control and Health Monitoring, 2008, pp 657-672

[5] Chang- Ming-Chia, Park-Sik -Kyu, Mullenix Alan and Spencer- F- Billie Jr Semiactive control strategy for a phase II smart base isolatedbenchmark building",Structural Control and Health Monitoring. 2008; 15:673 696

[6] Reigles Gary, Damon,"Smart Base Isolation Systems for Seismic Response Control Of Plan -Asymmetric Buildings", A Thesis, Rensselaer Polytechnic InstituteTroy, New York, 2005

[7] NarashimanSriram , "Control Of Smart Base Isolated Buildings With NewSemi Active Devices And Novel H2/LQG, Hq $\infty$ AndTime-Frequency Controllers", Rice University(2004)

[8] Su kimaHyun,Roschke N. Paul, "Design of fuzzy logic controller for smart base isolation system usinggenetic algorithm" Science Direct, Engineering Structures, 28, 2006, pp- 84-96

[9] Ozbulut E. Osman, Hurlebaus Stefan, "Fuzzy control of piezoelectric friction dampersfor seismic protection of smart base isolated buildings" Springer,Bull Earthquake Eng ,8,2010,pp-1435-1455

[10] Choi Min Kang, Jung Jo Hyung and Lee Won In, "Fuzzy Control Strategy For Seismic Response Reduction OfSmart Base Isolated Benchmark Building”, $17^{\text {th }}$ ASCE Engineering Conference, University of Delware, Newark, DE, June 2004,pp-1-8

[11] Kim Su Hyun, Roschke N Paul, " GA-Fuzzy Control Of Smart Base Isolated Benchmark BuildingUsing Supervisory Control Technique" Science Direct, Advances in Engineering Software, 38, (2007),pp- 453 465

Table 1. Max of evaluation criteria considering all the specifies earthquakes

\begin{tabular}{|c|c|c|c|c|c|c|c|c|c|c|c|}
\hline \multirow{2}{*}{$\begin{array}{l}\text { SI } \\
\text { no }\end{array}$} & \multirow[t]{2}{*}{ Author } & \multirow[t]{2}{*}{ Control Cases } & \multicolumn{9}{|c|}{ Performance Indices } \\
\hline & & & $\mathbf{J}_{1}$ & $\mathbf{J}_{2}$ & $\mathbf{J}_{3}$ & $\mathbf{J}_{4}$ & $\mathbf{J}_{5}$ & $\mathbf{J}_{6}$ & $\mathbf{J}_{7}$ & $\mathbf{J}_{8}$ & $\mathbf{J}_{9}$ \\
\hline 1. & ${\text { Ozbulut et } \mathrm{al}^{9}}^{9}$ & $\begin{array}{l}\text { i)Max Passive } \\
\text { ii)Optimal } \\
\text { iii)SVFLC } \\
\text { iv)SOFLC } \\
\text { Using piezoelectric } \\
\text { damper }\end{array}$ & $\begin{array}{l}.95 \\
.97 \\
.97 \\
.98\end{array}$ & $\begin{array}{l}.99 \\
1.04 \\
.96 \\
1\end{array}$ & $\begin{array}{l}.75 \\
.86 \\
.83 \\
.81\end{array}$ & $\begin{array}{l}1 \\
1 \\
.96 \\
1\end{array}$ & $\begin{array}{l}2.56 \\
1.95 \\
1.34 \\
1.62\end{array}$ & $\begin{array}{l}.59 \\
.52 \\
.36 \\
.45\end{array}$ & $\begin{array}{l}.59 \\
.73 \\
.74 \\
.72\end{array}$ & $\begin{array}{l}1.69 \\
1.56 \\
1.03 \\
1.05\end{array}$ & $\begin{array}{l}.94 \\
.87 \\
.9 \\
.93\end{array}$ \\
\hline 2. & Pozo et $\mathrm{al}^{13}$ & $\begin{array}{l}\text { i)F. Feedback } \\
\text { ii)Clipped } \\
\text { iii)Passive On } \\
\text { iv)Passive Off+(MR } \\
\text { Fluid dampers) }\end{array}$ & $\begin{array}{l}.83 \\
.82 \\
.81 \\
.83 \\
\end{array}$ & $\begin{array}{l}.83 \\
.81 \\
.82 \\
.86 \\
\end{array}$ & $\begin{array}{l}.59 \\
.54 \\
.48 \\
.41 \\
\end{array}$ & $\begin{array}{l}.85 \\
.87 \\
.94 \\
1.09 \\
\end{array}$ & $\begin{array}{l}.92 \\
1 \\
1.15 \\
1.40\end{array}$ & $\begin{array}{l}.29 \\
.33 \\
.45 \\
.14 \\
\end{array}$ & $\begin{array}{l}.44 \\
.36 \\
.28 \\
.23 \\
\end{array}$ & $\begin{array}{l}.59 \\
.57 \\
.59 \\
.58 \\
\end{array}$ & $\begin{array}{l}.73 \\
.79 \\
.85 \\
.88 \\
\end{array}$ \\
\hline 3. & Aliy et $_{\text {al }}{ }^{12}$ & $\begin{array}{l}\text { i)Lypunov } \\
\text { ii)FRB-FLC } \\
\text { iii)ARB-FLC } \\
+ \text { MRD }\end{array}$ & $\begin{array}{l}1.28 \\
1.52 \\
1.42\end{array}$ & $\begin{array}{l}1.26 \\
1.30 \\
1.46\end{array}$ & $\begin{array}{l}.79 \\
.86 \\
.81\end{array}$ & $\begin{array}{l}1.39 \\
1.18 \\
1.49\end{array}$ & $\begin{array}{l}1.62 \\
1.53 \\
1.58\end{array}$ & $\begin{array}{l}.43 \\
.43 \\
.40\end{array}$ & $\begin{array}{l}1.05 \\
.91 \\
.92\end{array}$ & $\begin{array}{l}1.85 \\
1.70 \\
1.53\end{array}$ & $\begin{array}{l}.48 \\
.51 \\
.46\end{array}$ \\
\hline 4. & Kim et $^{11}{ }^{11}$ & $\begin{array}{l}\text { i)Max Passive } \\
\text { ii)Clipped Optimal }\end{array}$ & $\begin{array}{l}.96 \\
1.25\end{array}$ & $\begin{array}{l}1 \\
1.2\end{array}$ & $\begin{array}{l}.68 \\
.74\end{array}$ & $\begin{array}{l}2.18 \\
1.37\end{array}$ & $\begin{array}{l}3.45 \\
2.08\end{array}$ & $\begin{array}{l}.69 \\
.38\end{array}$ & $\begin{array}{l}.46 \\
.51\end{array}$ & $\begin{array}{l}2 \\
.98\end{array}$ & $\begin{array}{l}.89 \\
.81\end{array}$ \\
\hline
\end{tabular}

[12] AliyFarqueandRamaswamyAnanth, "GA-Optimized FLC-Driven Semi-Active Control For Phase-II Smart Nonlinear Base-Isolated Benchmark Building"Structural Control And Health Monitoring, 2008; 15,pp-797 820

[13] PozoFrancesc, Rodriguez Arturo, Acho Leonardo, Vidal Yolanda, RodellearJos'e, "Force-derivative feedback semi-active control of base-isolated buildings usinglarge-scale MR fluid dampers", Proceedings of the 8th International Conference on Structural Dynamics, Eurodyn 2011,pp- 1839-1845

[14] PozoFrancesc,Acho Leonardo ，RodellarJos'e andRossell Maria Josep, "A Velocity-Based Seismic Control for Base-Isolated Building Structures", American Control Conference Hyatt Regency Riverfront, St. Louis, MO, USA(2009), pp-3908-3913

[15]Mehrkian Behnam,BaharArash, ChaibakhshAli , "Genetic Algorithm based Optimizationapproach for MR Dampers Fuzzy Modeling”, World Academy of Science, Engineering and Technology,5, 2011,pp-609615

[16]Leavitt J, Leavitt E J, Jabbari F and Yang N J, "Application of a high-pressure gas semi-active resettabledamper to the benchmark smart base-isolated building" Structural Control And Health Monitoring. 2005; 12, pp- 1-10

[17] DoppalapudiN.K, PalasaV.V, DatlaS.V and Saha P"Review On the Performance of Different Control Systems for Non-Linear Benchmark Building" IPCSIT ,28,2012, IACSIT Press, Singapore,pp- 167-172

[18] Mallik, A. K., Chatterjee S "Principal of Passive and active vibration control" Affiliated East-west press Private Limited, New Delhi (2014) 


\begin{tabular}{|c|c|c|c|c|c|c|c|c|c|c|c|}
\hline & & $\begin{array}{l}\text { iii)SV FLC1 } \\
\text { iv)SV FLC2 } \\
\text { v)SV-FLC3 } \\
+ \text { MRD }\end{array}$ & $\begin{array}{l}1.01 \\
1.02 \\
1.10\end{array}$ & $\begin{array}{l}1.04 \\
1.01 \\
1.08\end{array}$ & $\begin{array}{l}.94 \\
.95 \\
.85\end{array}$ & $\begin{array}{l}1.14 \\
1.27 \\
1.23\end{array}$ & $\begin{array}{l}1.39 \\
1.47 \\
1.58\end{array}$ & $\begin{array}{l}.69 \\
.69 \\
.61\end{array}$ & $\begin{array}{l}.69 \\
.69 \\
.61\end{array}$ & $\begin{array}{l}.81 \\
.81 \\
.86\end{array}$ & $\begin{array}{l}.81 \\
.81 \\
.8\end{array}$ \\
\hline 5. & Choi, Jung $^{10}$ & $\begin{array}{l}\text { linear elastometric } \\
\text { isolation } \\
\text { system+MRD } \\
\text { i)Sample controller } \\
\text { (LQG) } \\
\text { ii)Active } \\
\text { Fuzzy } \\
\text { iii)Semi active Fuzzy } \\
\text { Non Frictional } \\
\text { isolation } \\
\text { system+MRD } \\
\text { i)Active Fuzzy } \\
\text { ii)Semi active Fuzzy } \\
+ \text { +MRD }\end{array}$ & $\begin{array}{l}1.07 \\
1.08 \\
1.02 \\
1.12 \\
1.09\end{array}$ & $\begin{array}{l}1.09 \\
1.11 \\
1.02 \\
1.14 \\
1.19\end{array}$ & $\begin{array}{l}.97 \\
.96 \\
.92 \\
.95 \\
.91\end{array}$ & $\begin{array}{l}1.01 \\
1.03 \\
1.01 \\
1.26 \\
1.33\end{array}$ & $\begin{array}{l}1.06 \\
1.15 \\
1.04 \\
1.27 \\
1.35\end{array}$ & $\begin{array}{l}.18 \\
.28 \\
.14 \\
.22 \\
.22\end{array}$ & $\begin{array}{l}.8 \\
.9 \\
.76 \\
.91 \\
.94\end{array}$ & $\begin{array}{l}.89 \\
.85 \\
.85 \\
1.18 \\
1.2\end{array}$ & $\begin{array}{l}.52 \\
.77 \\
.63 \\
.22 \\
.27\end{array}$ \\
\hline 6. & Kima et al ${ }^{8}$ & $\begin{array}{l}\text { i)Passive on } \\
\text { ii)Skyhook } \\
\text { iii)Human Fuzzy } \\
\text { iv)GA-Fuzzy }\left(\mathrm{w}_{1}=.6\right) \\
\text { v)GA-Fuzzy }\left(\mathrm{w}_{2}=.7\right) \\
+ \text { FPS+MRD }\end{array}$ & $\begin{array}{l}.79 \\
.93 \\
.84 \\
.78 \\
.60\end{array}$ & $\begin{array}{l}1.41 \\
1.33 \\
1.32 \\
.95 \\
.96\end{array}$ & $\begin{array}{l}.47 \\
.96 \\
.57 \\
.56 \\
.45\end{array}$ & $\begin{array}{l}2.20 \\
1.66 \\
1.75 \\
1.26 \\
1.66\end{array}$ & $\begin{array}{l}1.41 \\
1.33 \\
1.32 \\
.95 \\
.98\end{array}$ & $\begin{array}{l}.79 \\
.81 \\
.77 \\
.77 \\
.76\end{array}$ & & & \\
\hline 7. & $\begin{array}{l}\text { Narasimhan and } \\
\text { Nagarajaiah }^{4}\end{array}$ & $\begin{array}{l}\text { i)Lypunov control } \\
\text { friction isolation } \\
\text { ii)Passive MRD- } \\
\text { Friction isolation } \\
\text { +FPS+LRB+MRD }\end{array}$ & $\begin{array}{l}1.44 \\
1.46\end{array}$ & $\begin{array}{l}1.26 \\
1.51\end{array}$ & $\begin{array}{l}.8 \\
.8\end{array}$ & $\begin{array}{l}1.39 \\
1.7\end{array}$ & $\begin{array}{l}1.73 \\
2.13\end{array}$ & $\begin{array}{l}.43 \\
.41\end{array}$ & $\begin{array}{l}1.05 \\
1.19\end{array}$ & $\begin{array}{l}1.85 \\
1.71\end{array}$ & $\begin{array}{l}.48 \\
.56\end{array}$ \\
\hline 8. & Erkus, Johnson $^{3}$ & $\begin{array}{l}\text { I)EQ Design } \\
\text { II)Final Design } \\
\text { +LRB }\end{array}$ & $\begin{array}{l}.89 \\
.95\end{array}$ & $\begin{array}{l}1.06 \\
1.07\end{array}$ & $\begin{array}{l}1.01 \\
1.01\end{array}$ & $\begin{array}{l}.96 \\
.94\end{array}$ & $\begin{array}{l}.99 \\
1.0\end{array}$ & $\begin{array}{l}.41 \\
.38\end{array}$ & $\begin{array}{l}.97 \\
1.02\end{array}$ & $\begin{array}{l}.89 \\
.91\end{array}$ & $\begin{array}{l}.23 \\
.27\end{array}$ \\
\hline 9. & $\begin{array}{l}\text { Nagarajaiah,and } \\
\text { Narasimhan }^{2}\end{array}$ & $\begin{array}{l}\text { i)Active Control } \\
\text { ii)Clipped Optimal } \\
\text { a)Passive } \\
\text { b)Control } \\
\text { iii)Skyhook Control } \\
\text { a)Passive } \\
\text { b)Control } \\
+ \text { MRD }\end{array}$ & $\begin{array}{l}.98 \\
.96 \\
1.25 \\
1.46 \\
1.43\end{array}$ & $\begin{array}{l}1.02 \\
1 \\
1.24 \\
1.51 \\
1.36\end{array}$ & $\begin{array}{l}.95 \\
.68 \\
.73 \\
.8 \\
.85\end{array}$ & $\begin{array}{l}.97 \\
2.18 \\
1.33 \\
1.7 \\
1.41\end{array}$ & $\begin{array}{l}1.02 \\
2.86 \\
2.08 \\
2.13 \\
1.59\end{array}$ & $\begin{array}{l}.15 \\
.69 \\
.38 \\
.39 \\
.45\end{array}$ & $\begin{array}{l}.8 \\
.46 \\
.46 \\
1.19 \\
1.05\end{array}$ & $\begin{array}{l}.87 \\
2 \\
.98 \\
1.63 \\
1.39\end{array}$ & $\begin{array}{l}.48 \\
.89 \\
.81 \\
.56 \\
.47\end{array}$ \\
\hline 10. & Gary Reigles $^{6}$ & $\begin{array}{l}\text { i)Max Passive } \\
\text { ii)Min Passive } \\
\text { iii)SVFLC } 1 \\
\text { iv)SVLFC } 2 \\
\text { v)SVFLC } 3 \\
\text { +CFV Damper }\end{array}$ & $\begin{array}{l}.56 \\
.93 \\
.61 \\
.67 \\
.75\end{array}$ & $\begin{array}{l}.46 \\
.83 \\
.51 \\
.54 \\
.62\end{array}$ & $\begin{array}{l}.34 \\
.80 \\
.38 \\
.43 \\
.48\end{array}$ & $\begin{array}{l}1.27 \\
.78 \\
.38 \\
1.73 \\
1.41\end{array}$ & $\begin{array}{l}.98 \\
1.00 \\
1.06 \\
1.09 \\
.93\end{array}$ & $\begin{array}{l}.78 \\
.95 \\
.86 \\
.88 \\
.82\end{array}$ & $\begin{array}{l}.48 \\
.74 \\
.52 \\
.56 \\
.61\end{array}$ & $\begin{array}{l}.82 \\
.83 \\
.81 \\
.82 \\
.81\end{array}$ & $\begin{array}{l}.76 \\
.18 \\
.72 \\
.70 \\
.46\end{array}$ \\
\hline 11. & Leavitt et al ${ }^{14}$ & $\begin{array}{l}\text { i)Reset off } \\
\text { ii)Reset active } \\
\text { iii)LQG(coc) } \\
\text { +Resettable stiffness } \\
\text { damper }\end{array}$ & $\begin{array}{l}1.33 \\
1.13 \\
1.26\end{array}$ & $\begin{array}{l}1.31 \\
1.13 \\
1.25\end{array}$ & $\begin{array}{l}1.25 \\
.92 \\
.74\end{array}$ & $\begin{array}{l}1.56 \\
1.22 \\
1.33\end{array}$ & $\begin{array}{l}1.21 \\
1.17 \\
1.47\end{array}$ & $\begin{array}{l}.16 \\
.24 \\
.38\end{array}$ & $\begin{array}{l}1.22 \\
.61 \\
.46\end{array}$ & $\begin{array}{l}1.43 \\
.81 \\
.98\end{array}$ & $\begin{array}{l}0 \\
.73 \\
.81\end{array}$ \\
\hline
\end{tabular}

8. Figure 

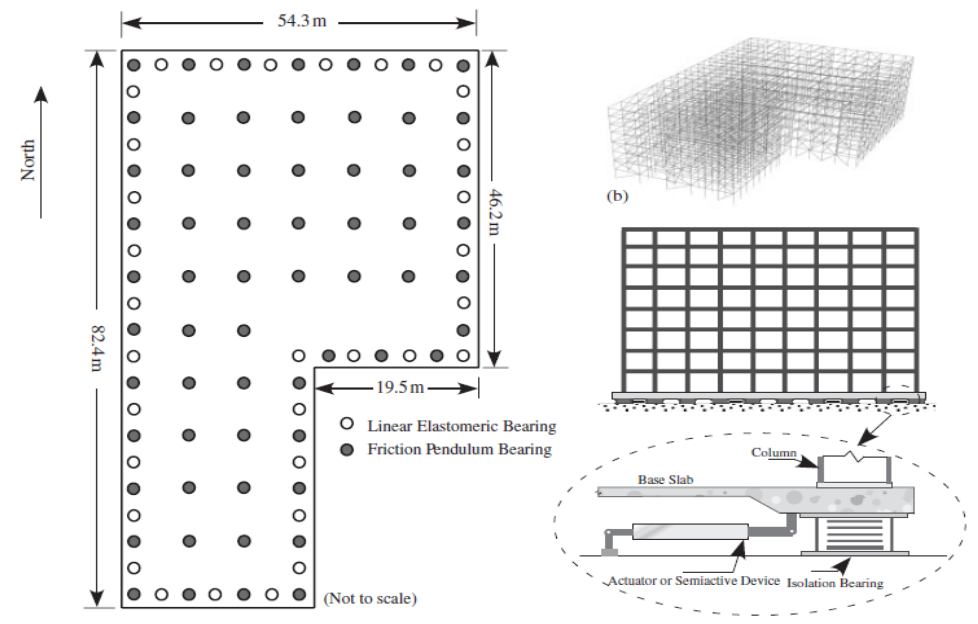

Figure 1 a)Plan of isolation b) FEM model c) elevation of the device in the structure ${ }^{1}$

Peak base shear

$J_{1}=\frac{\max _{t}\left\|V_{0}(t)\right\|}{\max _{t}\left\|\hat{V}_{0}(t)\right\|}$

Peak structural shear

$J_{2}=\frac{\max _{t}\left\|V_{1}(t)\right\|}{\max _{t}\left\|\hat{V}_{1}(t)\right\|}$

Peak base displacement

$J_{3}=\frac{\max _{t}\left\|x_{b}(t)\right\|}{\max _{t}\left\|\hat{x}_{b}(t)\right\|}$
Peak interstory drift

$J_{4}=\frac{\max _{t, f}\left\|d_{f}(t)\right\|}{\max _{t, f}\left\|\hat{d}_{f}(t)\right\|}$

Peak floor acceleration

$J_{5}=\frac{\max _{t, f}\left\|a_{f}(t)\right\|}{\max _{t, f}\left\|\hat{a}_{f}(t)\right\|}$

Peak control force

$J_{6}=\frac{\max _{t}\left\|f_{d}(t)\right\|}{\max _{t}\left\|V_{0}(t)\right\|}$
RMS base displacement

$J_{7}=\frac{\max _{i}\left\|\sigma_{d}(t)\right\|}{\max _{i}\left\|\hat{\sigma}_{d}(t)\right\|}$

RMS floor acceleration

$J_{8}=\frac{\max _{f}\left\|\sigma_{a}(t)\right\|}{\max _{f}\left\|\hat{\sigma}_{a}(t)\right\|}$

Energy dissipated by PFD

$J_{9}=\frac{\int_{0}^{T} f_{d}(t) \dot{x}_{b}(t) \mathrm{d} t}{\int_{0}^{T}\left\langle V_{0}(t) \dot{U}_{g}(t)\right\rangle \mathrm{d} t}$

Figure 2. Evaluation Criteria of smart base isolated benchmark building ${ }^{9}$

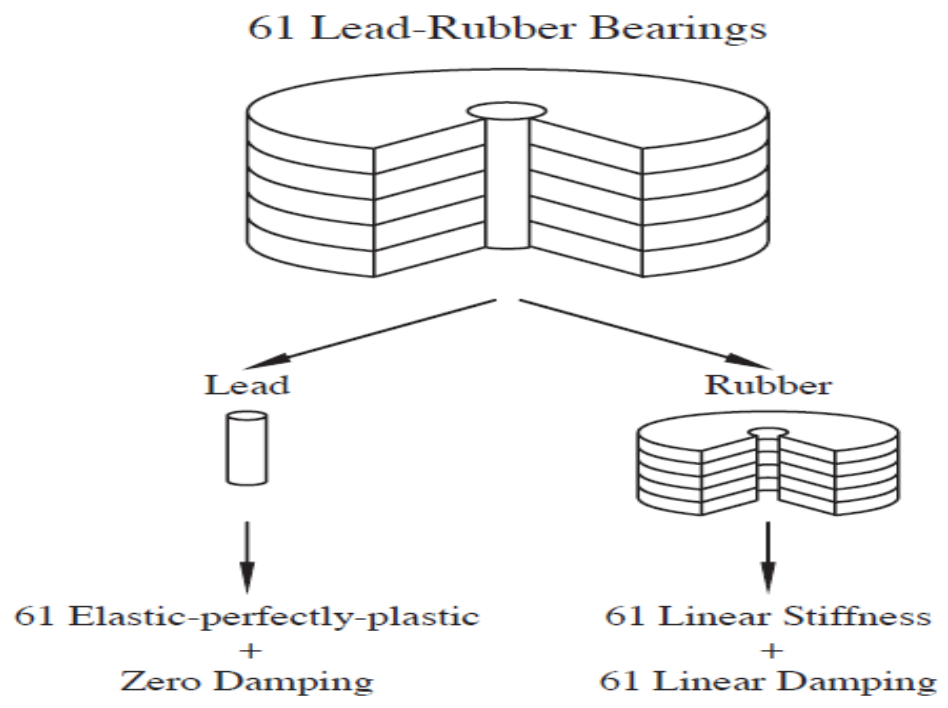

Figure 3. LRB Modeling ${ }^{3}$ 


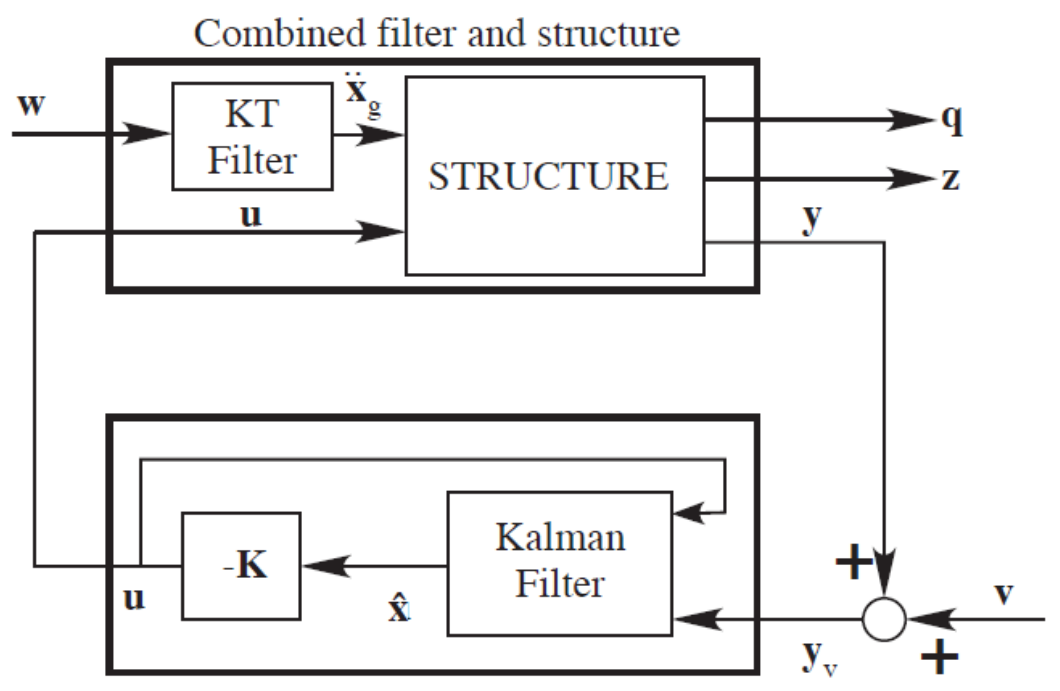

LQG Controller

Figure 4. augmented plant with LQG Controller ${ }^{3}$

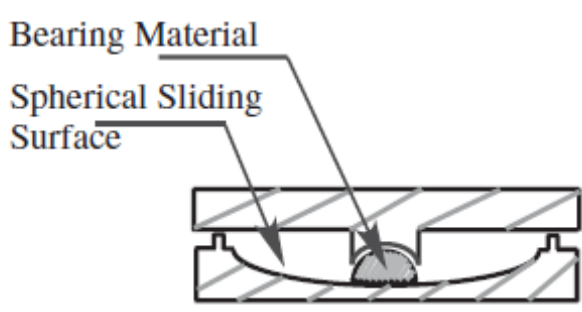

Friction Pendulum Bearing

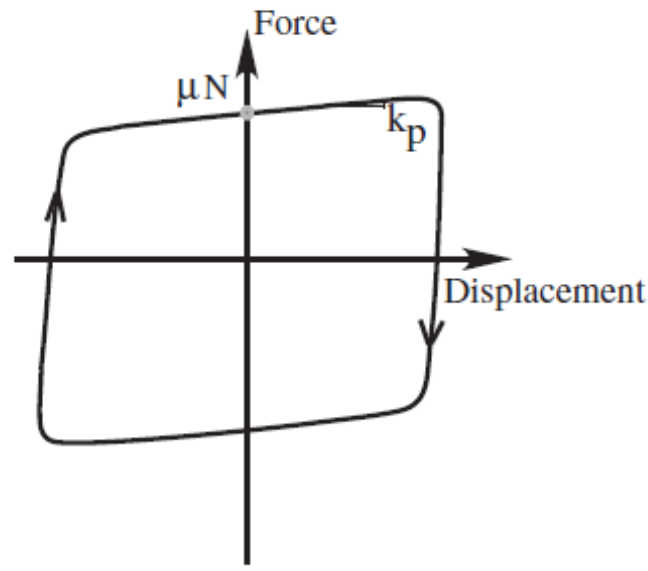

Figure 6. Force Displacement Curve of FPS ${ }^{1}$

(a)
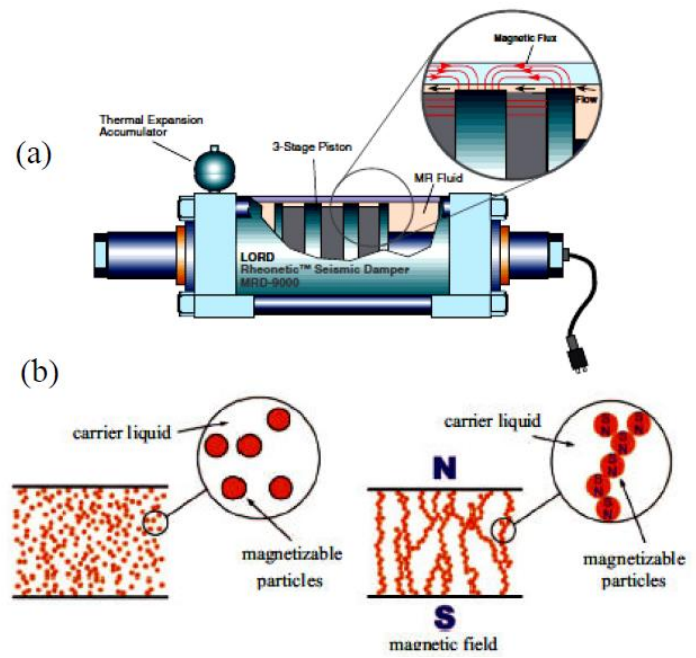

Figure 7. State of Fluid Behavior Before and after applying Magnetic field in MR Damper 


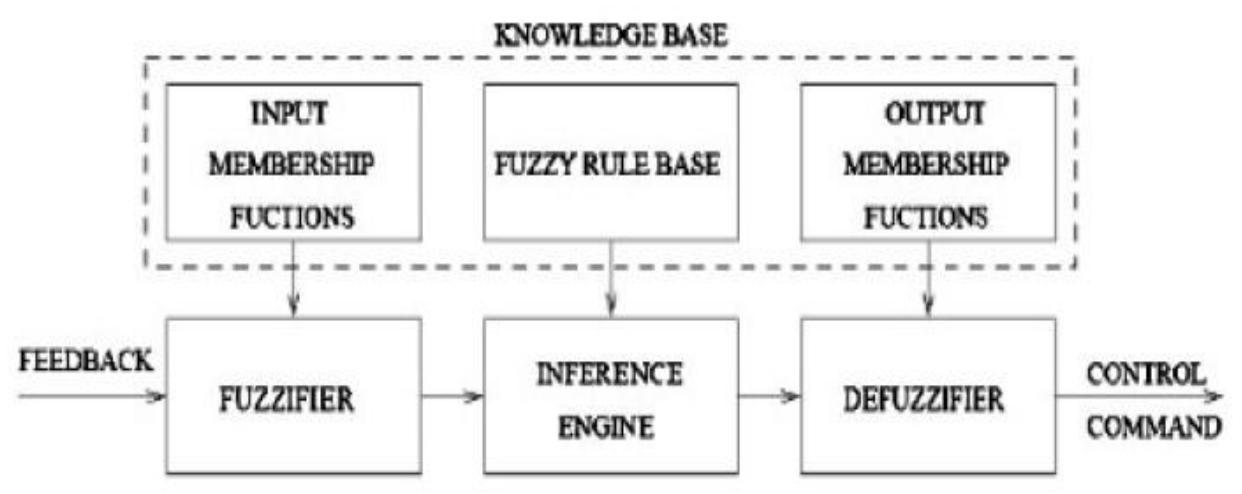

Figure 8. Design of FLC ${ }^{9}$

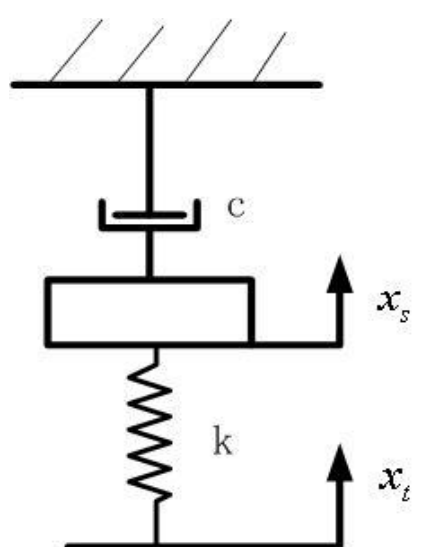

Figure 9 Schematic Diagram ofvibration isolation system with ideal Skyhook concept

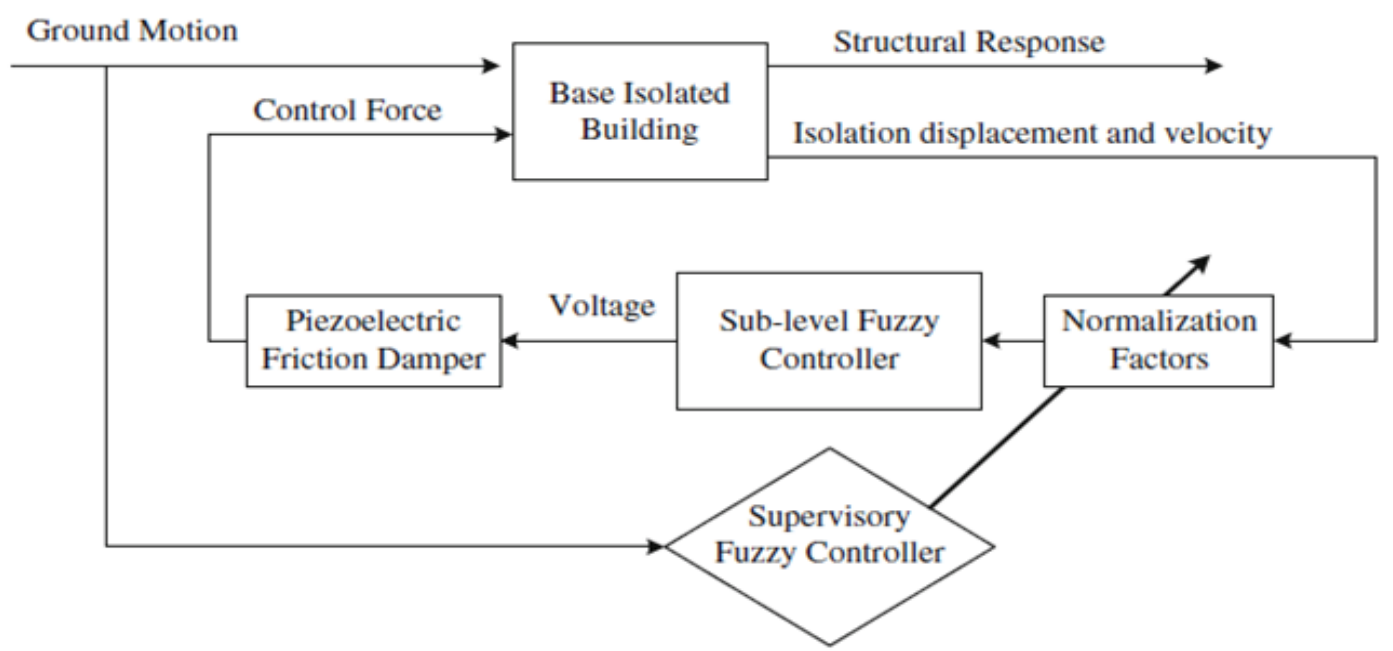

Figure 10. Block diagram of the system for SVFLC ${ }^{9}$ 


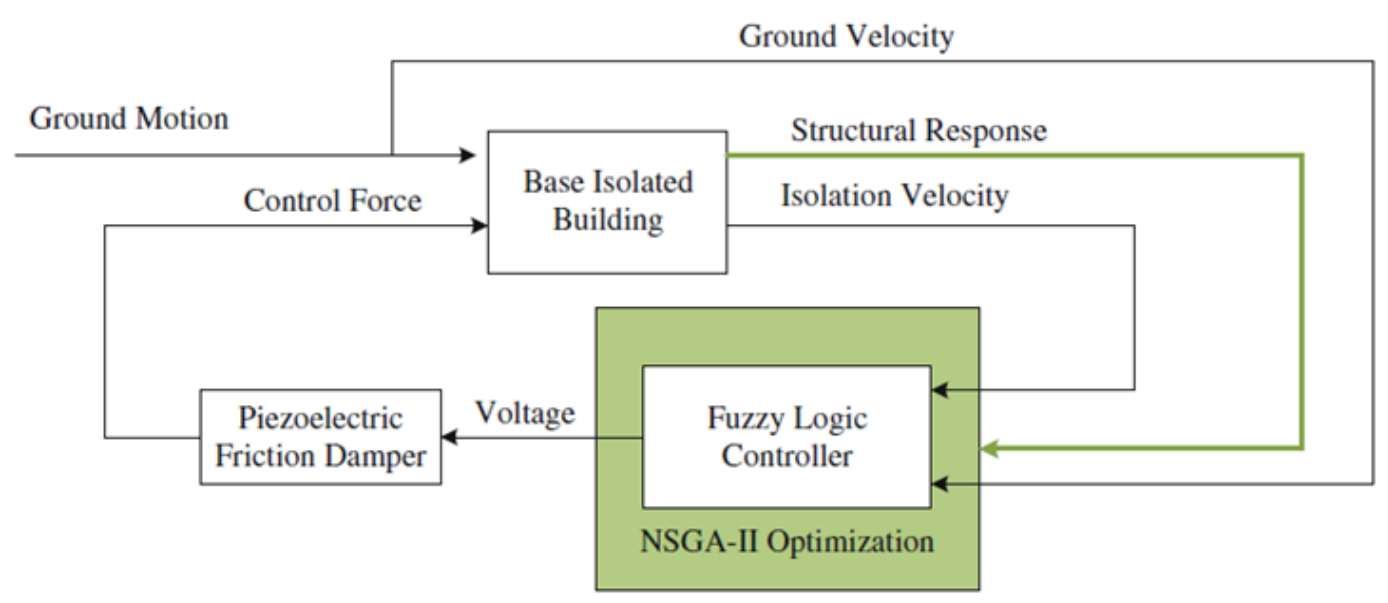

Figure 11. Block diagram of the system for self organizing fuzzy controller ${ }^{9}$

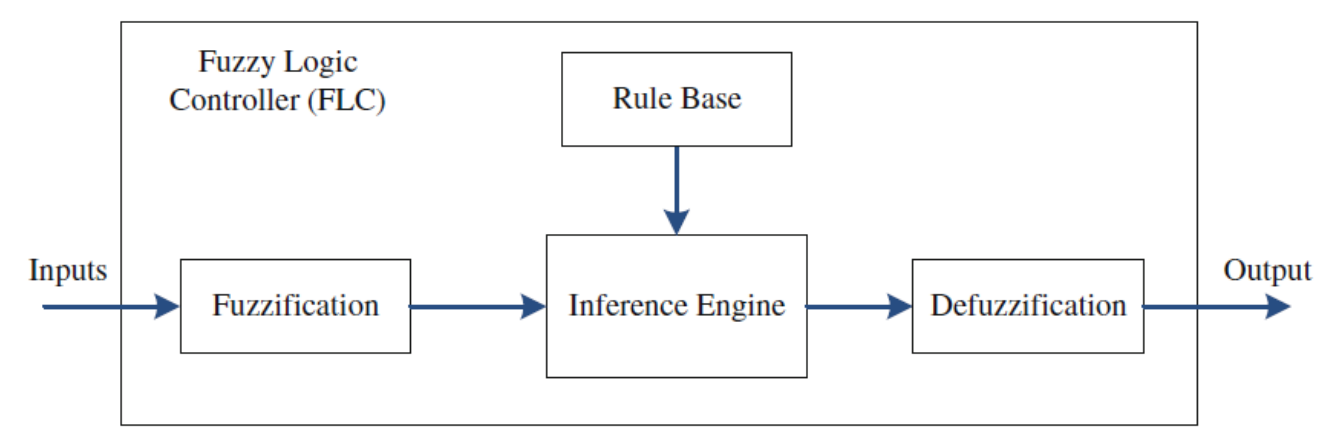

Figure 12. Basic Flowchart of FLC ${ }^{9}$

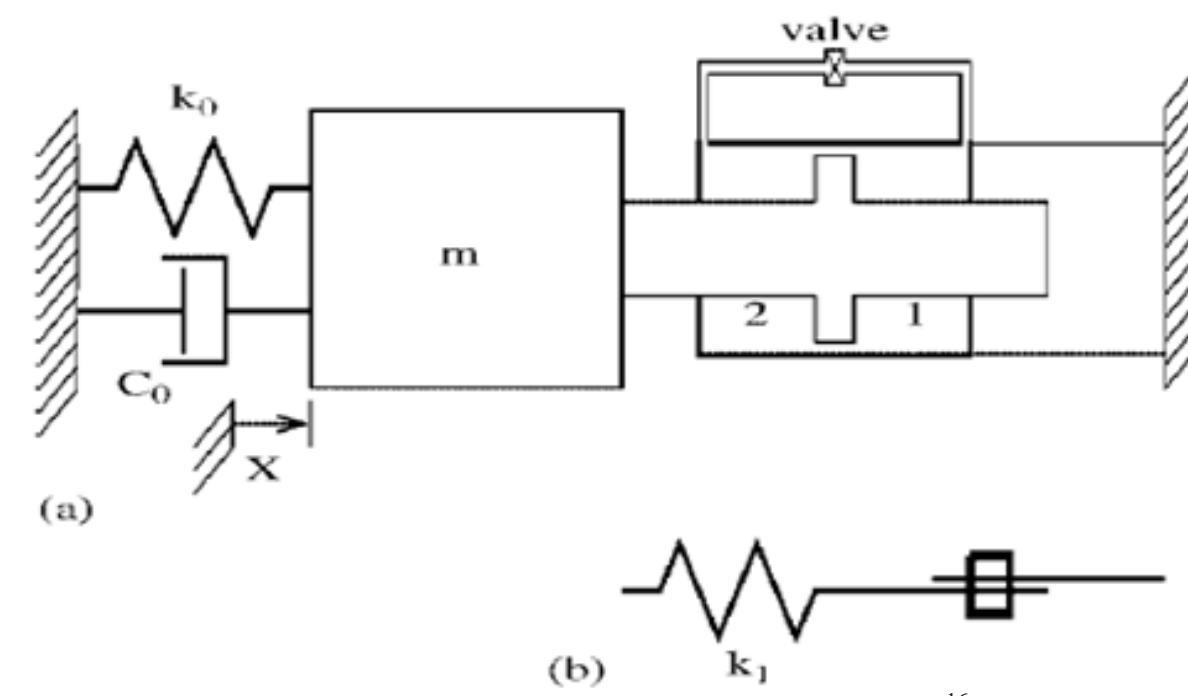

Figure 13. Schematic representing the resetting ${ }^{16}$ 


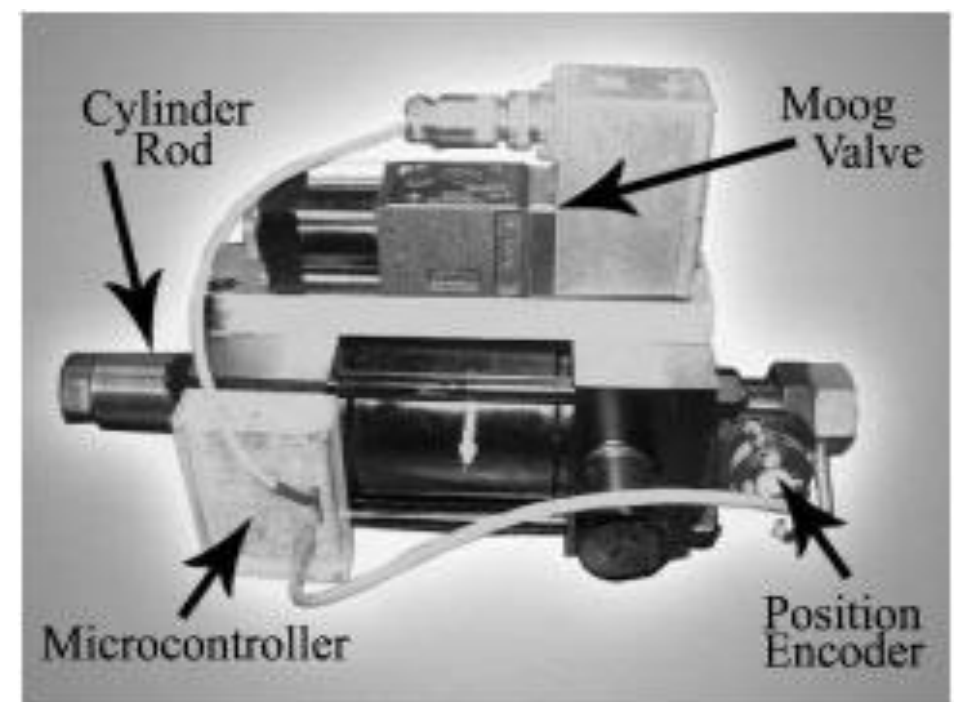

Figure 14. Variable Stiffness Damper enable of $120 \mathrm{KN}$ output ${ }^{16}$ 